\title{
The Sisyphean tasks of avoiding case cancellation
}

\author{
Martin Schuster, MD, MA
}

Department of Anesthesiology, Intensive Care, Emergency Medicine and Pain Therapy, Fürst-Stirum-Klinik Bruchsal, Academic Teaching Hospital, University of Heidelberg, Bruchsal, Germany

Cite as: Can Urol Assoc J 2013;7(5-6):174-5. http://dx.doi.org/10.5489/cuaj.1256

$\mathrm{T}$ he short-term cancellation of an elective procedure is an extraordinary challenge for process quality in surgical medicine. According to current literature, $5 \%$ to $20 \%$ of all elective surgery cases are cancelled the day of surgery. ${ }^{1-7}$ Cancelling or postponing an operation poses considerable emotional distress on the patient ${ }^{8}$ and leads to long and repetitive episodes of starving with relevant negative physiological effects. ${ }^{9}$ Furthermore, the patient and, in some cases, health insurance companies have to carry extra costs for the prolonged duration of treatment.

Case cancellations are also a big problem for hospitals. The final operating room (OR) plan aims to optimize the use of the very expensive OR resources. If cases are cancelled on short notice, it is unlikely that this goal can be reached. ${ }^{10}$ In addition, the cancelled patient has to be rescheduled; in most cases, this requires extra time and effort. For inpatients the hospital stay is prolonged; for the surgeon and anesthesiologist, the case has to fit in their usually tight schedule within the next days, which leads to even more administrative and procedural problems. ${ }^{11,12}$

Case cancellation has been reported by almost all surgical disciplines ${ }^{1-7}$ and a huge variety of reasons have been reported, including medical, OR-organization based or administrative reasons.

In the study presented in this issue of CUAJ, Leslie and colleagues looked at the specific situation in urology in an academic institution. ${ }^{13}$ They found a cancellation rate over the total 5-year study period of $9.5 \%$, which is well in the area described in previous studies. Interestingly they found a much higher cancellation rate in non-oncological cases. Additionally they took the effort to interview 29 of the 50 patients cancelled in the 2009 calendar year. Most patients interviewed said they were notified of the cancellation shortly before the surgery, some even less than an hour before the scheduled time of the operation. Most of the patients did not assume that postponing their surgical procedure had any negative impact on their health and over $60 \%$ agreed that the issue was handled appropriately. However, the patients did report a modest amount of additional emotional stress because of the cancellation.

The study sheds further light on the patients' perspective of cancellation. This is of great importance, because all too often medical institutions do not focus enough on this issue.

In a recent large multicentre study, I and my fellow colleagues found considerable differences in the case cancellation rate, not only among different disciplines, but also among hospitals of different sizes and academic status. ${ }^{7}$ University hospitals, especially, seem to face many challenges in organizing their OR-processes. Even within university hospitals, there are big differences in the case cancellation rate - a fact that cannot be explained by the type of surgery performed or the patients served in the specific institution.

We, therefore, must accept that it is largely in the hand of the single institution and its personnel: is the OR plan realistic or overbooked? Was the patient work up sufficient? Are the implicated physicians communicating well with each other? The driving force behind this is this question: How much do we care about it? Every institution should consider such a rigorous approach described in the study by Leslie and colleagues: measure the cancellation rate by predefined categorize and ask the patient about their perspective. ${ }^{13}$ It might sound like a Sisyphean task, but it would benefit all of us.

Competing interests: None declared.

\section{References}

1. Hand R, Levin P, Stanziola A. The causes of cancelled elective surgery. Qual Assur Util Rev 1990;5:2-6.

2. Lacqua MJ, Evans JT. Cancelled elective surgery: an evaluation. Am Surg 1994;60:809-11.

3. Schofield WN, Rubin GL, Piza M, et al. Cancellation of operations on the day of intended surgery at a major Australian referral hospital. Med J Aust 2005;182:612-5.

4. Sanjay P, Dodds A, Miller E, et al. Cancelled elective operations: an observational study from a district general hospital. J Health Organ Manag 2007;21:54-8. http://dx.doi.org/10.1108/14777260710732268

5. Argo IL, Vick CC, Graham LA, et al. Elective surgical case cancellation in the Veterans Health Administration system: identifying areas for improvement. Am J Surg 2009;198:600-6. http://dx.doi.org/10.1016/i. amisurg.2009.07.005

6. Seim AR, Fagerhaug T, Ryen SM, et al. Causes of cancellations on the day of surgery at two major university hospitals. Surg Innov 2009;16:173-80. http://dx.doi.org/10.1177/1553350609335035 
7. Schuster M, Neumann C, Neumann K, et al. The Effect of Hospital Size and Surgical Service on Case Cancellation in Elective Surgery. Results from a prospective multicenter study. Anesth Analg 2011;113:57885. http://dx.doi.org/10.1213/ANE.0b013e318222be4d

8. Tait AR, Voepel-Lewis T, Munro HM, et al. Cancellation of pediatric outpatient surgery: economic and emotional implications for patients and their families. J Clin Anesth 1997;9:213-9. http://dx.doi. org/10.1016/50952-8180(97)00032-9

9. Liungqvist 0, Soreide E. Preoperative fasting. Br I Surg 2003; 90:400-6. http://dx.doi.org/10.1002/ bjs. 4066

10. Basson MD, Butler TW, Verma H. Predicting patient nonappearance for surgery as a scheduling strategy to optimize operating room utilization in a Veterans' Administration hospital. Anesthesiology 2006;104:82634. http://dx.doi.org/10.1097/00000542-200604000-00029

11. Mangan JL, Walsh C, Kernohan WG, et al. Total joint replacement: implication of cancelled operations for hospital costs and waiting list management. Qual Health Care 1992;1:34-7. http://dx.doi. org/10.1136/qshc.1.1.34
12. van Klei WA, Moons KGM, Rutten CLG, et al. The effect of outpatient preoperative evaluation of hospital inpatients on cancellation of surgery and length of hospital stay. Anesth Analg 2002;94:644-9. http:// dx.doi.org/10.1097/00000539-200203000-00030

13. Leslie R, Beiko D, Van Vlymen J, et al. Day of surgery cancellation rates in urology: Identification of modifiable factors. Can Urol Assoc J 2013;7:167-73. http://dx.doi.org/10.5489/cuaj.12020

Correspondence: Dr. Martin Schuster, Department of Anesthesiology, Intensive Care, Emergency Medicine and Pain Therapy, Fürst-Stirum-Klinik Bruchsal, Academic Teaching Hospital, University of Heidelberg, Gutleutstr. 1-14, 76646 Bruchsal, Germany; fax: +49 7251-708 57509; martin. schuster@kliniken-k.de

\section{CUAJ JAUC}

Credit where credit is due!

Your work as a CUAJ reviewer is important. Please use your activity to earn valuable CME credits.

1. Login to the Royal College MAINPORT site (https://login.royalcollege.ca/pwmgr/ssoLogin. jsp), with your Royal College ID and password

2. From your dashboard, enter the CPD activity from the drop-down menu (i.e., Personal Learning Project, Section 2)

3. Indicate number of hours

4. Describe the title of the activity (i.e., Review of CUAJ submission CUAJ-12-111 [insert the appropriate manuscript number for the paper being reviewed])

5. Describe the outcome or the impact this review has had on your professional practice.

6. Indicate the date you completed the activity.

7. Once this information is inserted, you will receive an automatic number of credits (the number of credits earned is double the number of hours spent on the activity, 2 hours on the activity is worth 4 credits)

8. What resources did you use to learn? Check all that apply.
a. Audio/video
b. $\quad$ Group CME learning/elearning
c. Systematic reviews/meta-analysis
d. Reading activities/guidelines

9. What portion (\%) of this activity falls under the following CanMEDS roles?
a. Communicator
b. Professional
c. Scholar
d. Health advocate
e. Manager
f. Collaborator

10. Press the CONFIRM button - this will give you a summary of the activity.

You may include the article and upload the review form and any related documentation. 